\title{
Research on Construction Strategy of Energy Conservation and Emission Reduction in University Campuses in Beijing
}

\author{
Tang shengshi ${ }^{1}$, Zhao yuqing ${ }^{1{ }^{*},}$,Wangxu ${ }^{1}$,Deng jiayu ${ }^{1}$, Yang xin,Hou xiangyang ${ }^{1}$ \\ ${ }^{1}$ College of Architecture,North China University of Technology,Beijing 100144,China
}

\begin{abstract}
The per capita annual energy consumption of colleges and universities is much higher than the national per capita annual energy consumption, and the difference in energy consumption level among colleges and universities is also large, and the building energy conservation potential of colleges and universities is large. Taking a university in a cold region as an example, this paper made a statistical analysis of the comprehensive energy consumption in the past four years, and found that the proportion of energy consumption in the building environment energy system was the highest, accounting for $68.9 \%$. This paper puts forward the construction strategy of campus energy emission reduction for building environmental energy system, which not only provides support for scientific assessment of energy consumption level and energy saving, but also promots the policy of building energy saving transformation in existing universities.
\end{abstract}

\section{Introduction}

There are more than 2,000 universities in China, and the energy consumption of buildings accounts for $83.2 \%$ of the total energy consumption of colleges and universities $^{[1]}$, and the energy consumption of universities and colleges accounts for $8 \%$ of the total energy consumption of society ${ }^{[2]}$. The per capita annual energy consumption of colleges and universities is much higher than that of the whole country, and there is also a big difference in energy consumption level among colleges and universities, so the energy saving potential of buildings in colleges and universities is great ${ }^{[3]}$. The campus buildings of colleges and universities include office buildings, teaching buildings, laboratory buildings, dormitories, dining halls and bathrooms, etc. The energy consumption system of buildings mainly includes heating and air-conditioning system, lighting system, elevator and other power systems, domestic hot water system, scientific research and experimental equipment system, etc. The energy consumption types are electric power, natural gas and coal. The energy consumption of campus buildings is mainly reflected by the fact that campus buildings include buildings with different functions, and their energy consumption and energy consumption are also different. The distribution of time and place on campus is relatively concentrated and has obvious seasonal characteristics ${ }^{[4]}$. Almost all public buildings in universities in cold areas adopt centralized heating system, and the diversity of air conditioning system leads to the diversity of energy consumption of air conditioning system. Universities and colleges in developed countries have carried out researches on energy-saving and low-carbon campus earlier. Through energy consumption accounting research, corresponding low-carbon campus planning strategies, energy-saving and emission reduction development targets, quantitative evaluation and research methods have been put forward. In May 2008, 400 U.S. colleges and universities signed an agreement to make their campuses greener. Domestic high-carbon has not yet formed a clear emission reduction target, low-carbon campus construction is still in the initial stage ${ }^{[5][6]}$. Taking the building energy consumption of a university in Beijing as an example, the author takes the university campus in a cold region as the research target, makes use of the characteristics of building energy consumption in this region and the similarity of people's energy use behavior, analyzes the characteristics of building energy consumption in the campus, explores the potential of energy conservation and emission reduction, and provides support for the scientific assessment of energy consumption level and energy saving, and the promotion of energy-saving transformation policies of existing university buildings.

\section{Statistical analysis of energy consumption}

\subsection{Research Object}

The research object of this article is the northern industrial university campus in China's cold regions. The school is located in Shijingshan District, Beijing. The total construction area of the campus is about 400,000 square meters. The school has more than 15,000 students. The school's buildings are classified into educational research buildings, student dormitories, staff housing and logistics service class construction. The floor space of various

\footnotetext{
*Corresponding author: zyqbj@126.com
} 
types of houses and their proportions are detailed in Table 1 .

Table 1. Building and its classification statistics table

\begin{tabular}{|c|c|c|c|c|}
\hline $\begin{array}{c}\text { Serial } \\
\text { number }\end{array}$ & $\begin{array}{c}\text { Building } \\
\text { category }\end{array}$ & $\begin{array}{c}\text { Quantity } \\
\text { (building) }\end{array}$ & Building area $\left(\mathbf{m}^{\mathbf{2}}\right)$ & proportion (\%) \\
\hline 1 & $\begin{array}{c}\text { Educational } \\
\text { research } \\
\text { building }\end{array}$ & 12 & 160548 & $40.99 \%$ \\
\hline 2 & $\begin{array}{c}\text { student } \\
\text { dormitory }\end{array}$ & 11 & 126112 & $32.21 \%$ \\
\hline 3 & $\begin{array}{c}\text { Faculty } \\
\text { Residence }\end{array}$ & 13 & 56576 & $11.89 \%$ \\
\hline 4 & $\begin{array}{c}\text { Logistic service } \\
\text { building }\end{array}$ & 15 & 391640 & $10.91 \%$ \\
\hline 5 & total & 51 & $500 \%$ \\
\hline
\end{tabular}

a

\subsection{Energy consumption statistics}

North China University of Technology's energy consumption system is divided into three categories, namely the building environment energy system (including heating, air conditioning, ventilation, lighting systems), generalized production (service) energy systems (including data centers and vehicle systems), and comprehensive service energy systems. (Including elevators, domestic water systems, drinking water systems, office systems, domestic hot water systems, catering systems, and water systems). The main types of energy consumed by the energy system are electricity, natural gas, and gasoline.

\subsubsection{Energy Consumption Statistics}

A diagram of energy consumption is shown in Fig.1a. and the Fig.1b. ( electric power and natural gas is in Fig. 1a, gasoline is in Fig. 1b). The actual statistical unit of power consumption is $\mathrm{kWh}$, the natural gas statistical unit is $\mathrm{m}^{3}$, and the gasoline statistical unit is $\mathrm{t}$. In order to facilitate comparison and statistics of various consumption of energy, the amount of electricity, gas and fuel oil is converted to tce. ("tce" is the English abbreviation of "ton standard coal", the following "ton standard coal" are used in the abbreviated form. $\left.1 \mathrm{kWh}=0.34 \mathrm{kgce}, 1 \mathrm{~m}^{3}=1.21 \mathrm{kgce}, 1 \mathrm{t}=1.47 \mathrm{tce}\right)$.

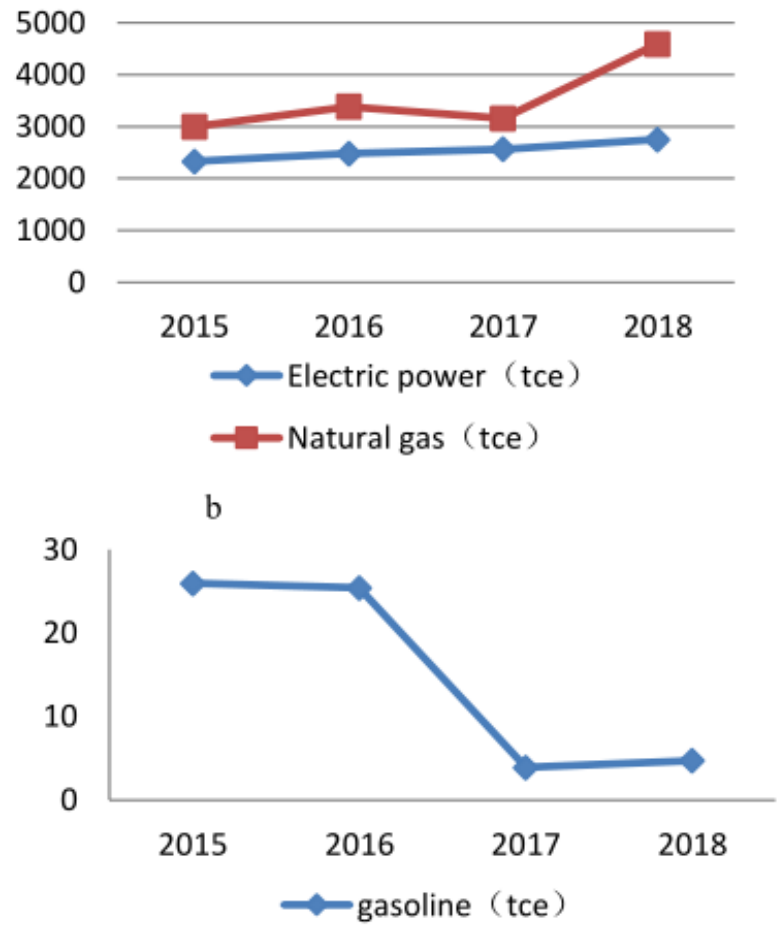

Fig.1. Diagram of energy consumption in the past four years

As can be seen from the energy chart, power consumption in the past three years has been rising at a uniform rate relative to the base year 2015. In the past three years, natural gas consumption has been on a rising and fluctuating trend compared with the base year. Gasoline consumption has been on a downward trend for the past three years. As for the total energy consumption, compared with the base year 2015, the total energy consumption from 2016 to 2018 is on the rise.

(2) Proportion of energy resource consumption

The energy consumption ratio data is used to draw the energy consumption proportion chart, as shown in Fig. 2. 


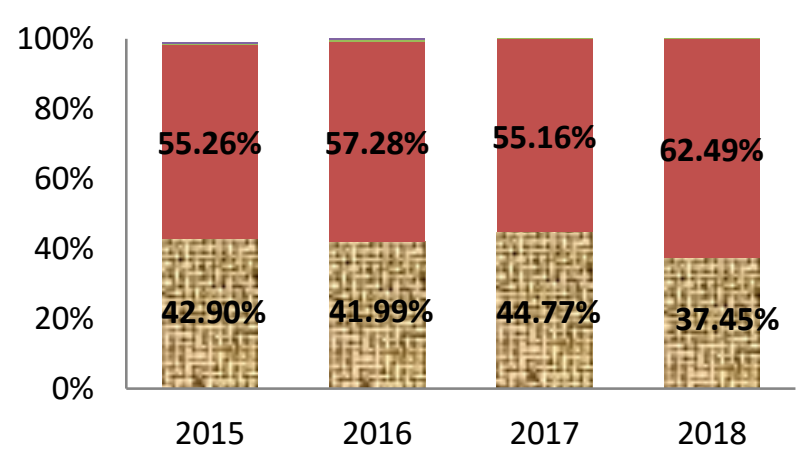

Electric power $\square$ Natural gas gasoline $\square$ diesel

Fig. 2. Proportion of energy consumption from 2015 to 2018

It can be seen from Fig.2. that natural gas consumption accounts for the largest proportion of total energy consumption, followed by electricity consumption, and gasoline consumption accounts for a very small proportion. It can be seen from the consumption structure of energy species that natural gas, The power consumption has great potential for energy conservation, and fully exploring its energy conservation potential will have a positive effect on achieving the energy conservation goals of the 13th Five-Year Plan.

According to the energy consumption data of the three subsystems, the energy consumption of building environment energy system, generalized production energy system and integrated service energy system accounted for $68.9 \%, 2.1 \%$ and $29 \%$, respectively. Reducing the total energy consumption should mainly start from the building environment energy system.

\subsubsection{Monthly consumption of energy resources}

The monthly consumption trends of electricity, natural gas, and water are shown in Fig. 3 and 5.

(1) Seasonal change in power consumption

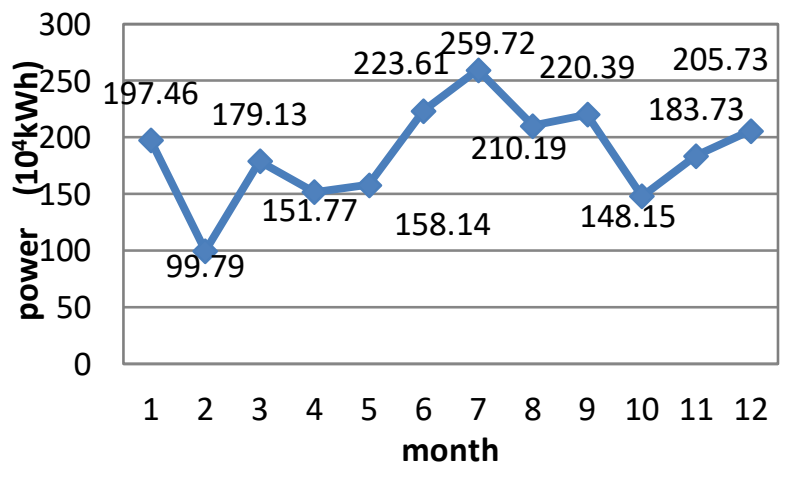

Fig. 3 Comparison of monthly power consumption in 2018

From the monthly power consumption comparison chart in 2018, it can be seen that February and October are the trough periods for the school's first half of the year, and October is in the transition season, that is, there is no heating and cooling power consumption. It is the normal office and teaching power consumption of the school. The number of teachers and students in the school during the winter vacation in February is small; the power consumption from January to March gradually decreases because the heating power consumption gradually decreases as the heating season ends; June Until September, the main electricity consumption was electricity for the air-conditioning system. Schools began heating in November and December, and their power consumption gradually increased.

(2) Seasonal change in natural gas consumption

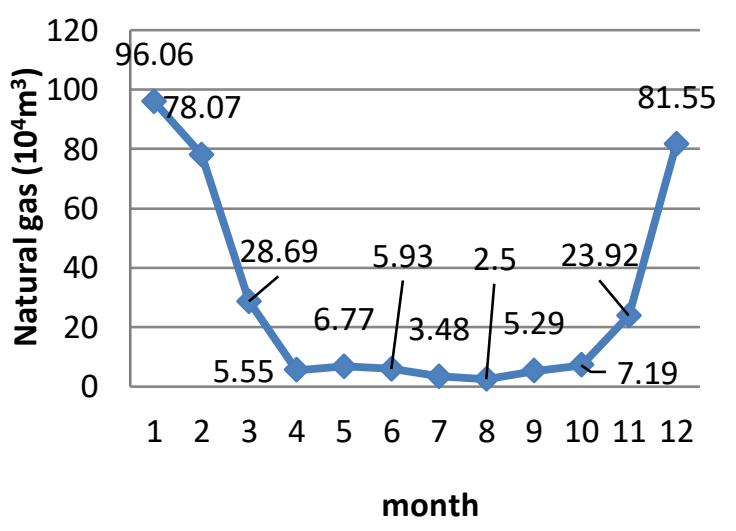

Fig. 4. Comparison of monthly gas consumption in 2018

According to the comparison results of the monthly consumption of natural gas in 2018 from the above figure, it can be seen that the natural gas consumption peak is from January to March, November and December, and the natural gas consumption trough is from April to October. The reason is that natural gas is mainly used in schools Heating and domestic hot water systems, from January to March, November and December are heating seasons, so their gas consumption is high, and from April to October, natural gas is mainly used for domestic hot water systems, so their gas consumption is small During the statistical period from 2015 to 2018, the average comprehensive energy consumption per student per year was $416.79 \mathrm{kgce} /$ person, the average comprehensive energy consumption per unit area per year was 16.67 $\mathrm{kgce} / \mathrm{m}^{2}$, and the average annual integrated $\mathrm{CO}_{2}$ emissions per student was 1.02t/a. Compared with Shenyang University 3.04t/a, Liaoning University 2.56 $\mathrm{t} / \mathrm{a}$, Shenyang University of Technology 1.4t/a, and Northeastern University3.11t/a, etc. ${ }^{[7]}$, the comparative coefficient of per capita carbon emissions in the university district of North China University of Technology is at a relatively low level.

\section{Conclusions and construction strategies}

How to achieve sustainable development of energy-saving campuses needs to quantify the interaction among the various influencing factors of campus energy consumption, so as to determine the share of each influencing factor in the overall campus energy consumption and the corresponding emission reduction strategies . The energy consumption of the campus must 
ensure the matching and coordination among the factors from the perspective of system integrity, improve energy efficiency, and improve the overall function of the system.

\subsection{Economizing design and transformation of building monolith}

The single building shape realizes the passive use of solar energy, rationally controls the building shape coefficient and increases the external surface area that can be received by solar energy, and realizes the multi-effect utilization of solar energy.The materials and construction forms of building envelopes meet the requirements of energy-saving design. The maintenance and renovation of the envelope structure should be pay attention, so as to reduce the heating and cooling energy requirements.

\subsection{Energy-saving debugging and updating of equipment systems}

Install variable frequency speed regulation equipment for the refrigeration pump and cooling pump motors of the central air-conditioning system, and use temperature difference control to adjust the speed of the motors to achieve the purpose of saving energy consumption; the lighting control system in public areas is replaced with an intelligent induction control system;

\subsection{Focus on behavior energy conservation publicity and education}

In addition to the above-mentioned building energy-saving transformation and equipment system update, teachers and students should strengthen their awareness of energy conservation. For example, if the indoor air-conditioning set temperature is increased in summer, the electric power will decrease by $5-10 \%$ when the indoor temperature is increased by $1{ }^{\circ} \mathrm{C}$.In the winter, the indoor temperature cannot be too high.You can adjust the indoor temperature by adjusting the opening of the valve to avoid cooling and energy waste.

\section{Acknowledgements}

Fund project: Beijing university students scientific research and entrepreneurship action plan project (216051360019XN030) north China university of technology.

\section{References}

1. Dongle Xian, Research and implementation of campus energy consumption monitoring and energy consumption analysis system [D]. Chengdu: University of electronic science and technology of China

2. Tan HongWei, Xu yulin, hu chengyi, et al. Research on energy management of building campus [J].
Building energy \&Environment, 2010, (1): 29-36-40.

3. Yin liangliang, Analysis of energy saving potential of a university in tianjin and energy consumption prediction based on energy consumption survey [D]. Tianjin: tianjin university,2010.

4. Gao biao, tan hongwei, song yachao. Energy consumption of campus buildings: a case study of a comprehensive university [J]. Building energy efficiency, 2011, 39 (2):41-44.

5. GUORu, TIAN Yinghan. Low-carbon oriented methodology of energy-related carbon accounting and its application in campus[J]. Journal of Tongji University (natural sciences edition), 2015, 43 (9):1361-1366.

6. WANG Xiaobin, LIU Yuncai, PENG Suyuan, et al. Onuniversity campus construction under background of low-carboneconomy[J]. Journal of Hunan Universtiy of Technology (socialsciences edition), 2013, 18(5): 7-9.

7. LI Guangjun, GUXiaowei, WANG Qing, et al. Ecological footprint and ecological efficiency of the universities in Shenyang City[J]. Resources science, 2005, 27(6):140 -145. 